Review Article

\title{
Effects of Probiotic Supplement in Pregnant Women with Gestational Diabetes Mellitus: A Systematic Review and Meta- Analysis of Randomized Controlled Trials
}

\author{
Jiayue Zhang, Shujuan Ma, Shilan Wu, Chuhao Guo, Sisi Long, and Hongzhuan Tan \\ Department of Epidemiology and Biostatistics, Xiangya School of Public Health, Central South University, Changsha, Hunan, China \\ Correspondence should be addressed to Hongzhuan Tan; tanhz99@qq.com
}

Received 9 April 2019; Revised 11 July 2019; Accepted 7 August 2019; Published 5 September 2019

Academic Editor: Antonio Brunetti

Copyright (C) 2019 Jiayue Zhang et al. This is an open access article distributed under the Creative Commons Attribution License, which permits unrestricted use, distribution, and reproduction in any medium, provided the original work is properly cited.

Background. Previous studies showed that probiotics could improve glycemic control and attenuate some of the adverse effects of type 2 diabetes. However, whether the effects are generalizable to gestational diabetes mellitus (GDM) remains uncertain. Objective. We conducted a systematic review and meta-analysis to evaluate the effects of probiotic supplement in GDM. Method. PubMed, EMBASE, the Cochrane Library, and EBSCO were systematically searched for relevant literature published through January 2019. Randomized controlled trials (RCTs) assessing the effects of probiotic supplement on one or more of the following in GDM were included: pregnancy outcome (the primary outcome), glycemic control, blood lipid profile, and inflammation and oxidative stress. Two reviewers independently extracted data and assessed the risk of bias in studies. Meta-analysis was conducted by using the fixed effects model unless substantial heterogeneity was found among studies. Results. Eleven randomized trials involving 719 participants were included for analysis. Eight of the trials were from Iran. Probiotics were given alone in eight trials and synbiotics in three trials. Though the components of probiotics varied, Lactobacillus was included in all trials and Bifidobacterium in all except one. The duration of intervention ranged from 4 to 8 weeks. Almost all trials (10/11) had a low risk of bias. Probiotic supplementation reduced the risk of a newborn's hyperbilirubinemia by $74 \%$ and improved four biomarkers for glycemic control (fasting blood glucose, fasting serum insulin, homeostasis model assessment insulin resistance, and quantitative insulin sensitivity check index), two biomarkers for lipid profile (triglycerides and HDL-cholesterol), and four biomarkers for inflammation and oxidative stress (total glutathione, malondialdehyde, nitric oxide, and total antioxidant capacity). But significant heterogeneity was observed in the meta-analyses on the four biomarkers related to glycemic control and on triglycerides, which could not be explained by prespecified subgroup analyses according to the mean age of participants and intervention type (i.e., probiotics or synbiotics). The effects on the risk of preterm delivery, macrosomia and a newborns' hypoglycemia, gestational age, total cholesterol, and LDL-cholesterol were not statistically significant. Conclusion. Probiotic supplementation seemed to be able to reduce the risk of a newborn's hyperbilirubinemia and improve glycemic control, blood lipid profiles and inflammation and oxidative stress in pregnant women with GDM. However, due to the heterogeneity among existing studies, the surrogate nature of outcomes, and/or the fact that most studies were from Iran, the clinical significance and generalizability of the above findings remain uncertain. Further studies are warranted to address the limitations of existing evidence and better inform the management of GDM.

\section{Introduction}

Gestational diabetes mellitus (GDM) is defined as any degree of glucose intolerance that occurs or is first recognized during pregnancy $[1,2]$. GDM was reported to be associated with various obstetric complications, such as hydramnios, preterm delivery, and cesarean delivery [3], and adverse outcomes of fetuses or newborns, such as congenital malformation, fetal death [4], and neonatal respiratory distress syndrome $[2,5]$. In addition, both mothers with GDM and their infants were at an increased risk of diabetes mellitus and metabolic dysfunction in later life [6]. 


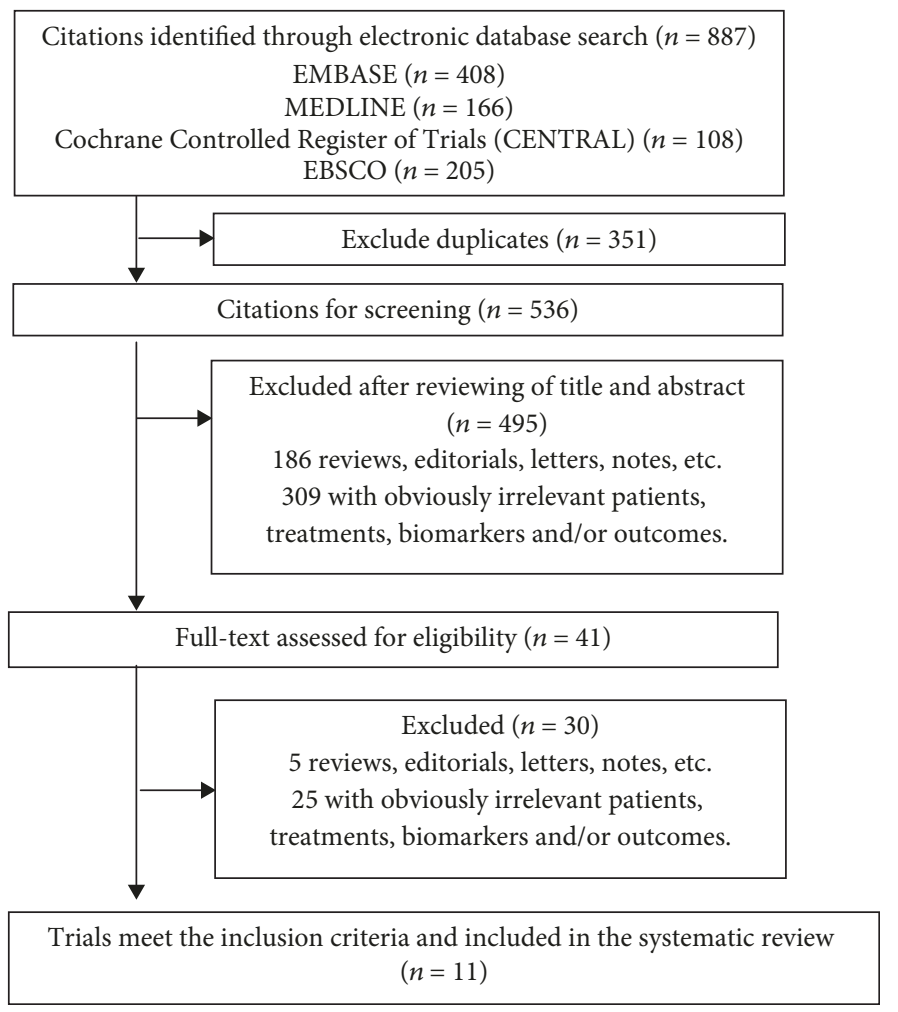

FIgURE 1: Flowchart of literature selection.

Probiotics was defined by the Food and Agriculture Organization/World Health Organization as "live microorganisms which when administered in adequate amounts confer a health benefit on the host" [7-9]. Probiotics may reinoculate or balance the host's gut microbiota, which are associated with diabetes and other metabolic diseases [10-12]. They can be given as biological supplements or in food such as yogurt [13-15], making them readily available for consumption [16-18].

Previous studies showed that probiotics could improve glycemic control $[9,19-22]$ and attenuate some of the adverse effects of type 2 diabetes [23]. However, whether the effects are generalizable to GDM remains uncertain. For example, Babadi et al. [24] found that probiotic supplementation could improve fasting blood glucose in pregnant women with GDM, while Ahmadi et al. [25] found that there was no statistically significant difference between probiotics and placebo in glycemic control. Thus, we conducted a systematic review to summarize all available trials and provide a full picture of the effects of probiotics on both hard and surrogate outcomes.

\section{Materials and Methods}

This review was conducted in accordance with the PRISMA statement [26].

2.1. Eligibility Criteria. Randomized controlled trials that allocated pregnant women with GDM to an intervention group receiving probiotic supplements or to a control group receiving placebo and reported at least one of the following outcomes were included: (1) pregnancy outcomes (the primary outcome of this systematic review)-preterm birth, macrosomia, gestational age, newborns' hyperbilirubinemia, and newborns' hypoglycemia; (2) blood glucose and related indicators-fasting blood glucose (FBG), fasting serum insulin (FSI), homeostasis model assessment insulin resistance (HOMA-IR), and quantitative insulin sensitivity check index (QUICKI); (3) blood lipid profiles-triglycerides, total cholesterol, LDL-cholesterol, and HDL-cholesterol; and (4) biomarkers of inflammation and oxidative stress-total glutathione (GSH), malondialdehyde (MDA), nitric oxide (NO), and total antioxidant capacity (TAC). To be eligible, probiotics could be given alone or together with prebiotics, which are nondigestible carbohydrates that nourish probiotics and healthy bacteria. The combination of probiotics and prebiotics is usually referred to as synbiotic.

2.2. Literature Search and Study Selection. PubMed, Cochrane, EBSCO, and EMBASE were searched for relevant literature published through January 2019 with the following terms: (probiotic* OR synbiotic* OR lactobacill* OR streptococc $*$ OR bifidobacter* OR saccharomy* OR yeast OR yogurt OR bacteria* OR acidophilus OR ferment* OR microorganism $*$ ) AND (pregnan* OR gestation* OR matern* OR obstetric* OR expectan*) AND (random* OR trial $*$ OR placebo OR blind $*$ ) AND (diabetes OR glucose). Two reviewers screened titles and abstracts of the retrieved records to select potentially eligible studies, for which full texts were obtained and examined to determine their eligibility. The reference lists of eligible studies and relevant reviews were manually checked for additional studies. Duplicate publications were excluded. 
TABLE 1: Characteristics of the included studies.

\begin{tabular}{|c|c|c|c|c|c|c|c|}
\hline Study & Year & Country & $\begin{array}{l}\text { Intervention/control } \\
\quad \text { (sample size })\end{array}$ & $\begin{array}{c}\text { Age } \\
\text { (intervention/control) }\end{array}$ & $\begin{array}{l}\text { Duration } \\
\text { (weeks) }\end{array}$ & Probiotic species & $\begin{array}{l}\text { Total } \\
\text { dose } \\
(\mathrm{CFU})\end{array}$ \\
\hline Ahmadi et al. & 2016 & Iran & $\begin{array}{c}\text { Synbiotic/placebo } \\
(35 / 35)\end{array}$ & $28.5 \pm 5.8 / 28.7 \pm 3.4$ & 6 & $\begin{array}{l}\text { Lactobacillus acidophilus } \\
\text { Lactobacillus casei } \\
\text { Bifidobacterium bifidum }\end{array}$ & $6 \times 10^{9}$ \\
\hline Babadi et al. & 2018 & Iran & $\begin{array}{l}\text { Probiotic/placebo } \\
\text { (24/24) }\end{array}$ & $29.0 \pm 4.2 / 28.8 \pm 4.3$ & 6 & $\begin{array}{l}\text { Lactobacillus acidophilus } \\
\text { Lactobacillus casei } \\
\text { Bifidobacterium bifidum } \\
\text { Lactobacillus fermentum }\end{array}$ & $8 \times 10^{9}$ \\
\hline Badehnoosh et al. & 2018 & Iran & $\begin{array}{c}\text { Probiotic/placebo } \\
\text { (30/30) }\end{array}$ & $27.8 \pm 3.7 / 28.8 \pm 5.4$ & 6 & $\begin{array}{l}\text { Lactobacillus acidophilus } \\
\text { Lactobacillus casei } \\
\text { Bifidobacterium bifidum }\end{array}$ & $6 \times 10^{9}$ \\
\hline Dolatkhah et al. & 2015 & Turkey & $\begin{array}{c}\text { Probiotic/placebo } \\
\text { (29/27) }\end{array}$ & $28.1 \pm 6.2 / 26.5 \pm 5.2$ & 8 & $\begin{array}{c}\text { Lactobacillus acidophilus LA-5 } \\
\text { Bifidobacterium BB-12 } \\
\text { Streptococcus thermophilus } \\
\text { STY-31 } \\
\text { Lactobacillus delbrueckii } \\
\text { bulgaricus LBY-27 }\end{array}$ & $>4 \times 10^{9}$ \\
\hline Jafarnejad et al. & 2016 & Iran & $\begin{array}{c}\text { Probiotic/placebo } \\
(41 / 41)\end{array}$ & $32.4 \pm 3.1 / 31.9 \pm 4.0$ & 8 & $\begin{array}{l}\text { Streptococcus thermophilus } \\
\text { Bifidobacterium breve } \\
\text { Bifidobacterium longum } \\
\text { Bifidobacterium infantis } \\
\text { Lactobacillus acidophilus } \\
\text { Lactobacillus plantarum } \\
\text { Lactobacillus paracasei } \\
\text { Lactobacillus delbrueckii } \\
\text { subsp. Bulgaricus }\end{array}$ & $15 \times 10^{9}$ \\
\hline Kijmanawat et al. & 2018 & Thailand & $\begin{array}{c}\text { Probiotic/placebo } \\
(28 / 29)\end{array}$ & $32.5 \pm 5.0 / 30.7 \pm 5.1$ & 4 & $\begin{array}{l}\text { Bifidobacterium } \\
\text { Lactobacillus }\end{array}$ & $2 \times 10^{9}$ \\
\hline Lindsay et al. & 2015 & Ireland & $\begin{array}{c}\text { Probiotic/placebo } \\
(74 / 75)\end{array}$ & $33.5 \pm 5.0 / 32.6 \pm 4.5$ & 6 & Lactobacillus salivarius & $1 \times 10^{9}$ \\
\hline Nabhani et al. & 2018 & Iran & $\begin{array}{c}\text { Synbiotic/placebo } \\
(45 / 45)\end{array}$ & $29.4 \pm 5.8 / 30.3 \pm 5.6$ & 6 & $\begin{array}{l}\text { L. acidophilus } \\
\text { L. plantarum } \\
\text { L. fermentum } \\
\text { L. gasseri }\end{array}$ & $9.2 \times 10^{10}$ \\
\hline Jamilian et al. & 2018 & Iran & $\begin{array}{c}\text { Probiotic/placebo } \\
(29 / 28)\end{array}$ & $31.2 \pm 5.9 / 29.9 \pm 3.7$ & 6 & $\begin{array}{l}\text { Lactobacillus acidophilus } \\
\text { Bifidobacterium bifidum } \\
\text { L. reuteri } \\
\text { Lactobacillus fermentum }\end{array}$ & $8 \times 10^{9}$ \\
\hline Karamali et al. & 2016 & Iran & $\begin{array}{c}\text { Probiotic/placebo } \\
(30 / 30)\end{array}$ & $31.8 \pm 6.0 / 29.7 \pm 4.0$ & 6 & $\begin{array}{l}\text { Lactobacillus acidophilus } \\
\text { L. casei } \\
\text { Bifidobacterium bifidum }\end{array}$ & $6 \times 10^{9}$ \\
\hline Karamali et al. & 2018 & Iran & $\begin{array}{c}\text { Synbiotic/placebo } \\
(30 / 30)\end{array}$ & $27.2 \pm 5.9 / 26.2 \pm 3.1$ & 6 & $\begin{array}{l}\text { Lactobacillus acidophilus } \\
\text { L. casei } \\
\text { Bifidobacterium bifidum }\end{array}$ & $6 \times 10^{9}$ \\
\hline
\end{tabular}

2.3. Data Extraction and Quality Assessment. The following data were extracted from eligible studies: first author, year of publication, country of study, number of trial participants, mean age of participants, details of intervention (e.g., probiotic species and probiotic counts measured by colonyforming unit), intervention duration, and main results on the interested outcomes. Data extraction was conducted independently by two reviewers. Disagreements between the two were resolved by discussion until a consensus was achieved. The methodological quality of the included trials was assessed by using the Cochrane Risk of Bias tool for Quality Assessment of Randomized Controlled Trials [27]. This tool rates six domains of primary research, i.e., random sequence generation, allocation concealment, blinding of participants and personnel, blinding of outcome assessment, incomplete outcome data, and selective reporting. If a study had four or more domains (including the "random sequence generation" domain or the "allocation concealment" domain) at a low risk of bias and none at a high risk, the study as a whole would be rated as having low risk bias [16]. 
2.4. Statistical Analyses. RevMan 5.3 software was used for conducting meta-analysis. For binary outcomes, i.e., preterm delivery, macrosomia, newborns' hyperbilirubinemia, and newborns' hypoglycemia, risk ratios (RRs) with 95\% confidence intervals (CIs) were combined across relevant studies. For the other outcomes which are all continuous, the differences in prepost changes between the probiotic and placebo groups were combined. The fixed effects model was used for meta-analysis, unless substantial heterogeneity was found among studies. A $P$ value $\leq 0.10$ for Cochran's $Q$ test or an $I^{2} \geq 50 \%$ was suggestive of substantial heterogeneity, in which case subgroup analyses according to the mean age of participants and the type (probiotic or synbiotic), duration, and dose of intervention were conducted to explore the potential sources. Sensitivity analyses were conducted by excluding the studies with high risk bias to examine the robustness of results. Potential publication bias was assessed using a funnel plot if 10 or more studies were included in a meta-analysis [28]. A two-tailed $P<0.05$ was considered statistically significant for all analyses except heterogeneity tests.

\section{Results}

A total of 887 citations were identified by literature search, and 11 randomized trials [24, 25, 29-37] involving 719 participants were finally included in this systematic review (Figure 1). Characteristics of the included studies are shown in Table 1. Eight trials were from Iran, while the other three were from Ireland, Turkey, and Thailand, respectively. The mean age of participants ranged from 26.2 to 33.5 and was above 30 years in 5 studies. Probiotics were given alone in eight trials and synbiotics in three trials. The composition of probiotics varied between studies, but all trials included Lactobacillus, and all except one trial included Bifidobacterium. The duration of intervention ranged from 4 to 8 weeks.

All except one study were considered having a low risk of bias, as assessed using the Cochrane Collaboration Risk of Bias tool (Figure 2). The study by Lindsay et al. was considered having a high risk because the number of participants available for analysis of some outcomes was much smaller than originally randomized.

The results of meta-analyses are summarized in Figures 3-6. For pregnancy outcomes, probiotic supplementation reduced the incidence of a newborn's hyperbilirubinemia by $74 \%$ (RR: $0.26,95 \%$ CI: $0.12,0.55$ ), whereas no statistically significant difference was observed in other outcomes between the probiotic and placebo groups. For secondary outcomes, probiotic supplementation improved FBG (mean difference: $-4.11 \mathrm{mg} / \mathrm{dL}, 95 \% \mathrm{CI}:-7.42,-0.80$ ), FSI (mean difference: $-2.40 \mu \mathrm{IU} / \mathrm{mL}, 95 \%$ CI: $-3.43,-1.37$ ), HOMA-IR (mean difference: $-0.68,95 \%$ CI: $-0.93,-0.43$ ), QUICKI (mean difference: 0.01, 95\% CI: 0.01, 0.01), triglycerides (mean difference: $-18.59 \mathrm{mg} / \mathrm{dL}, 95 \% \mathrm{CI}:-26.69$, -10.49), HDL-cholesterol (mean difference: $2.23 \mathrm{mg} / \mathrm{dL}$, 95\% CI: $0.86,3.60$ ), NO (mean difference: $1.29 \mu \mathrm{mol} / \mathrm{L}$, 95\% CI: $0.42,2.16$ ), TAC (mean difference: $63.78 \mathrm{mmol} / \mathrm{L}$, 95\% CI: $37.20,90.36$ ), GSH (mean difference: $23.13 \mu \mathrm{mol} / \mathrm{L}$, 95\% CI: 0.65, 45.62), and MDA (mean difference: $-0.38 \mu \mathrm{mol} / \mathrm{L}$,

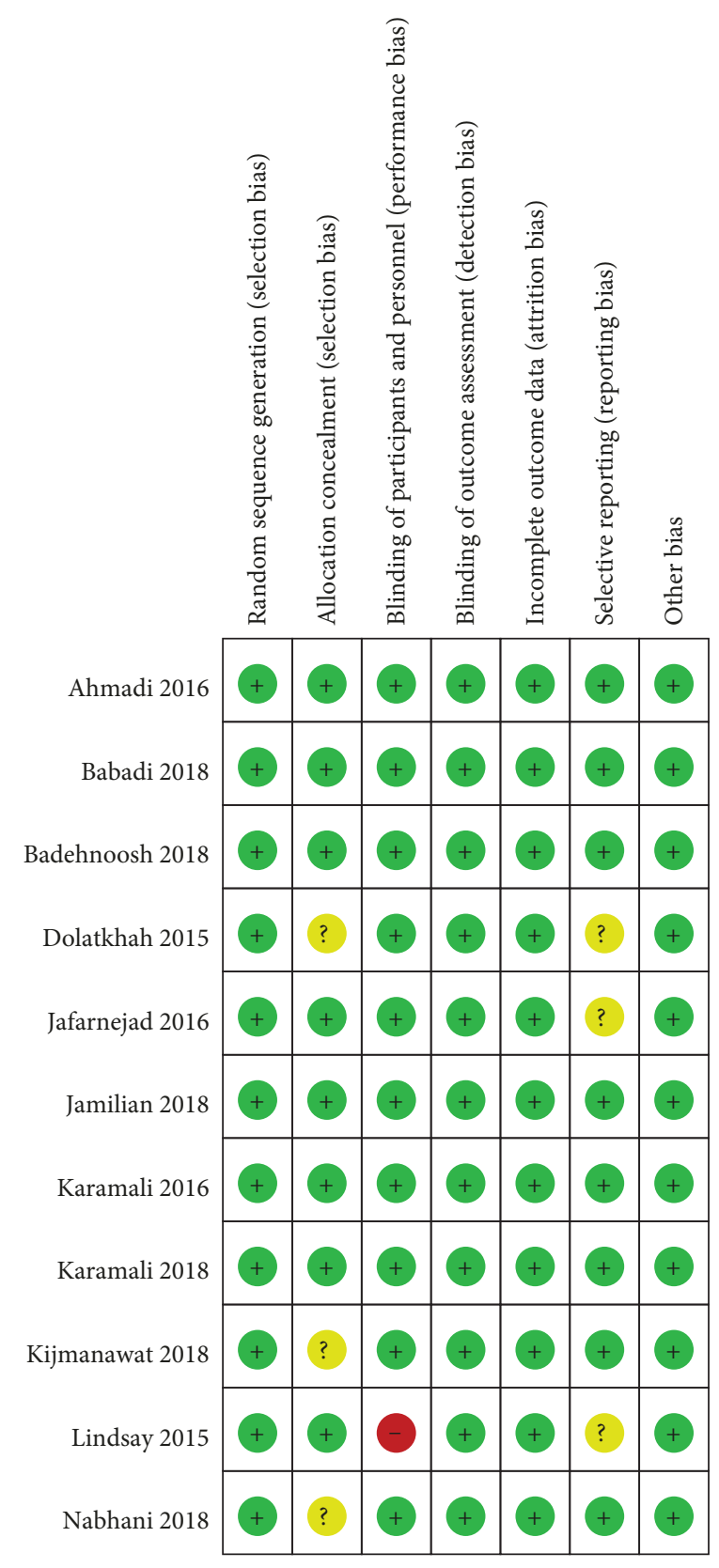

FIGURE 2: Risk of bias among included randomized controlled trials.

95\% CI: $-0.57,-0.19)$ but had no effects on total cholesterol and LDL-cholesterol.

3.1. Subgroup, Sensitivity, and Publication Bias Analysis. Substantial heterogeneity was observed in the meta-analyses for blood glucose and related indicators, triglycerides, and macrosomia. As the data on the duration and dose of probiotic intervention could not be grouped appropriately, subgroup analyses to investigate the potential source of heterogeneity were conducted according to the mean age of participants and the type of intervention only (Table 2). The results showed that the effects of probiotics on FBG, FSI, HOMA-IR, QUICKI, and macrosomia varied considerably by age, while none of the results of meta-analyses changed with the type of intervention. This indicates that the 


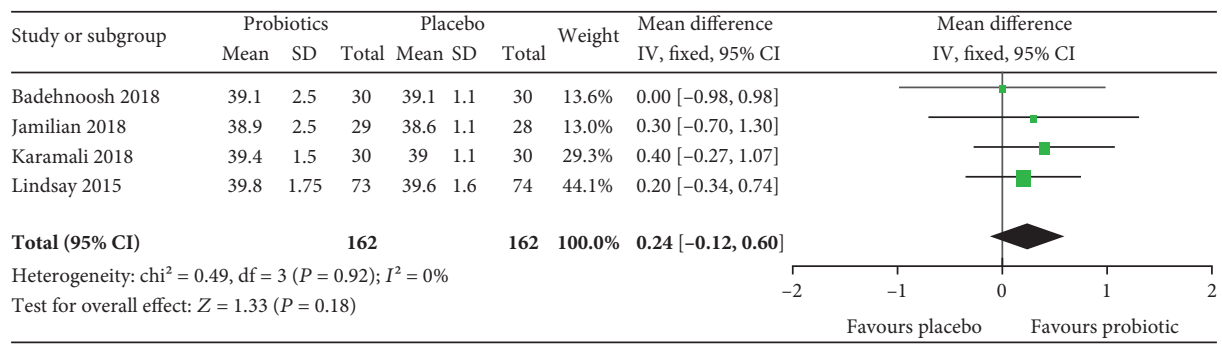

(a)

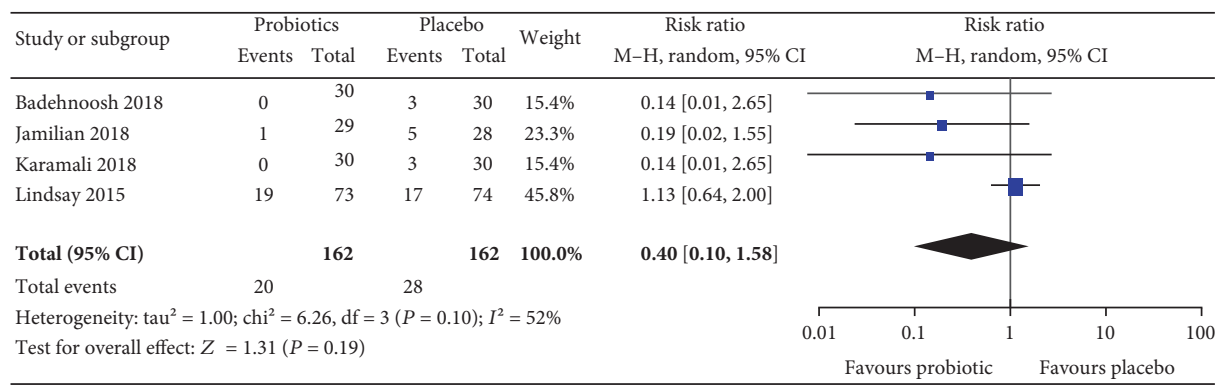

(b)

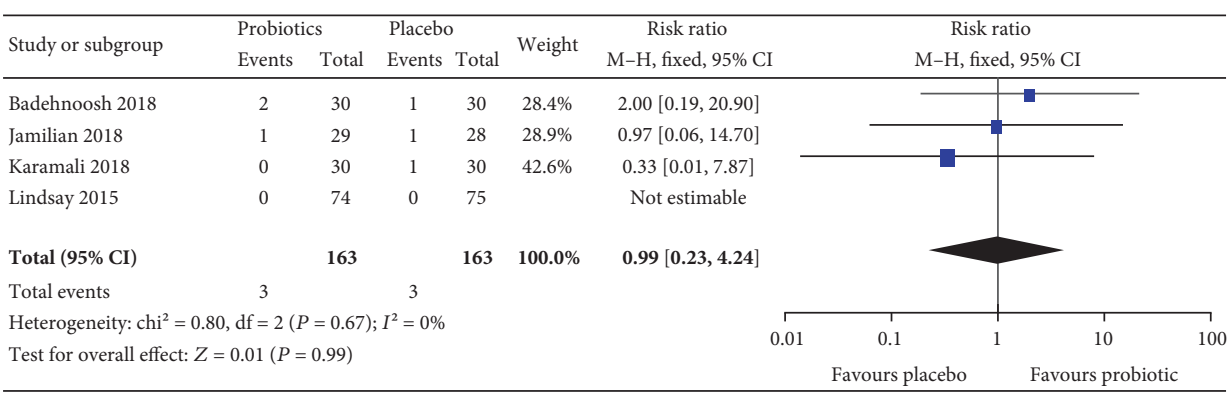

(c)

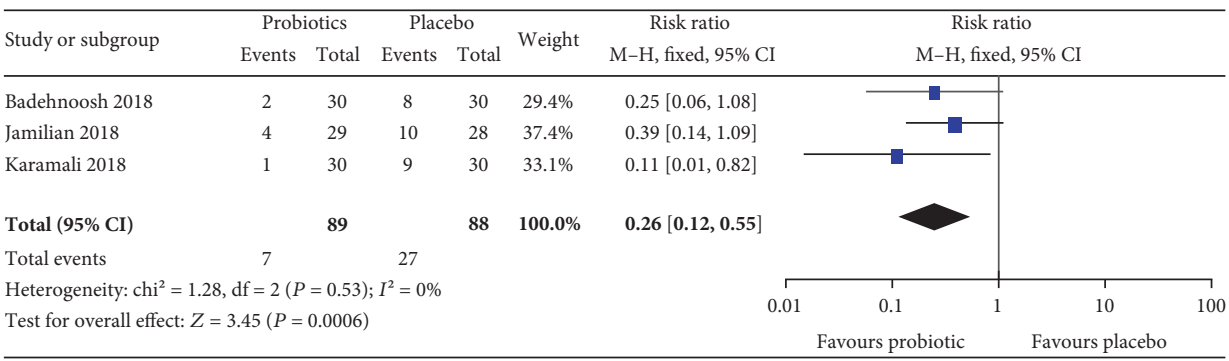

(d)

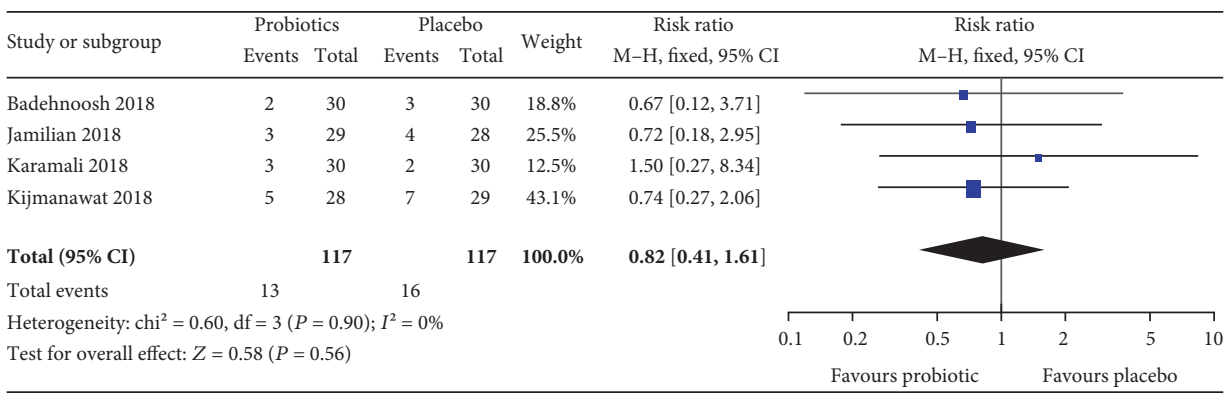

(e)

FIGURE 3: Effect of probiotic supplementation on pregnancy outcomes: (a) gestational age (weeks), (b) the incidence of macrosomia, (c) the incidence of preterm delivery, (d) the incidence of newborns' hyperbilirubinemia, and (e) the incidence of newborns' hypoglycemia in pregnant women with gestational diabetes. 


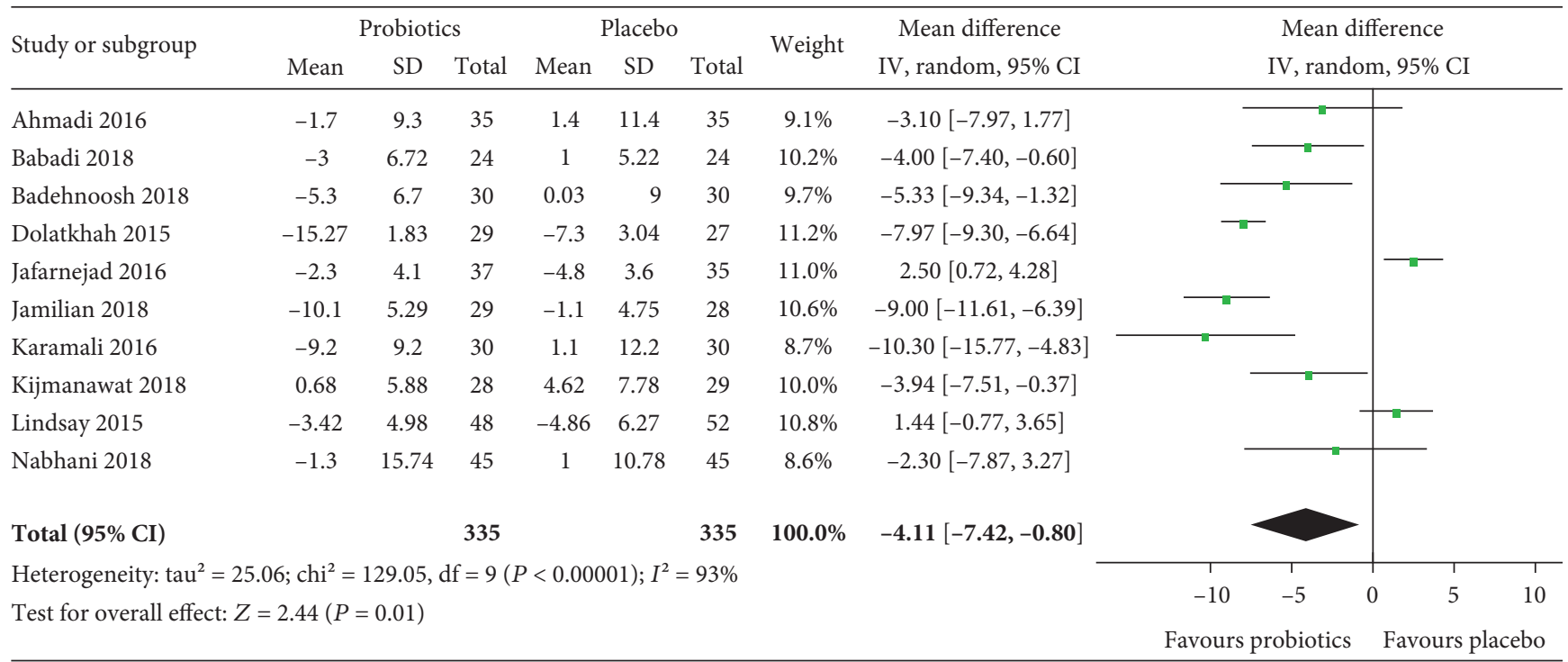

(a)

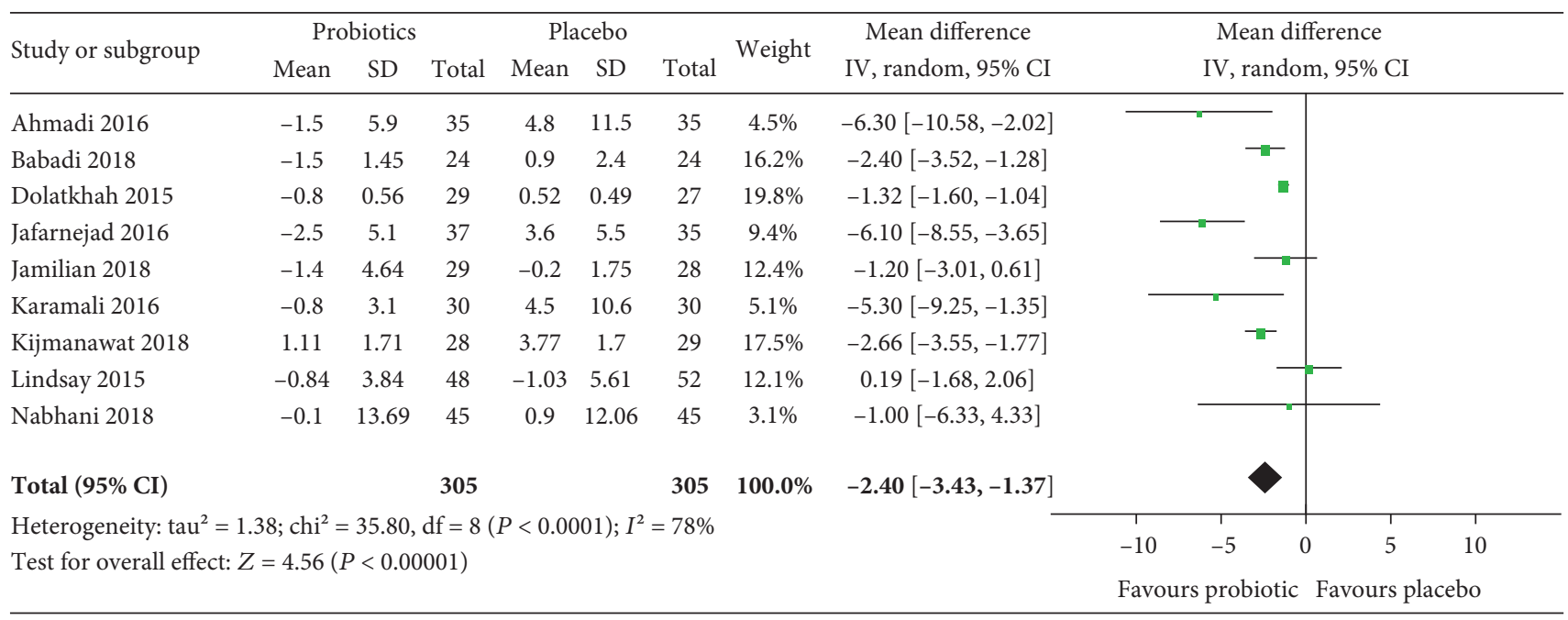

(b)

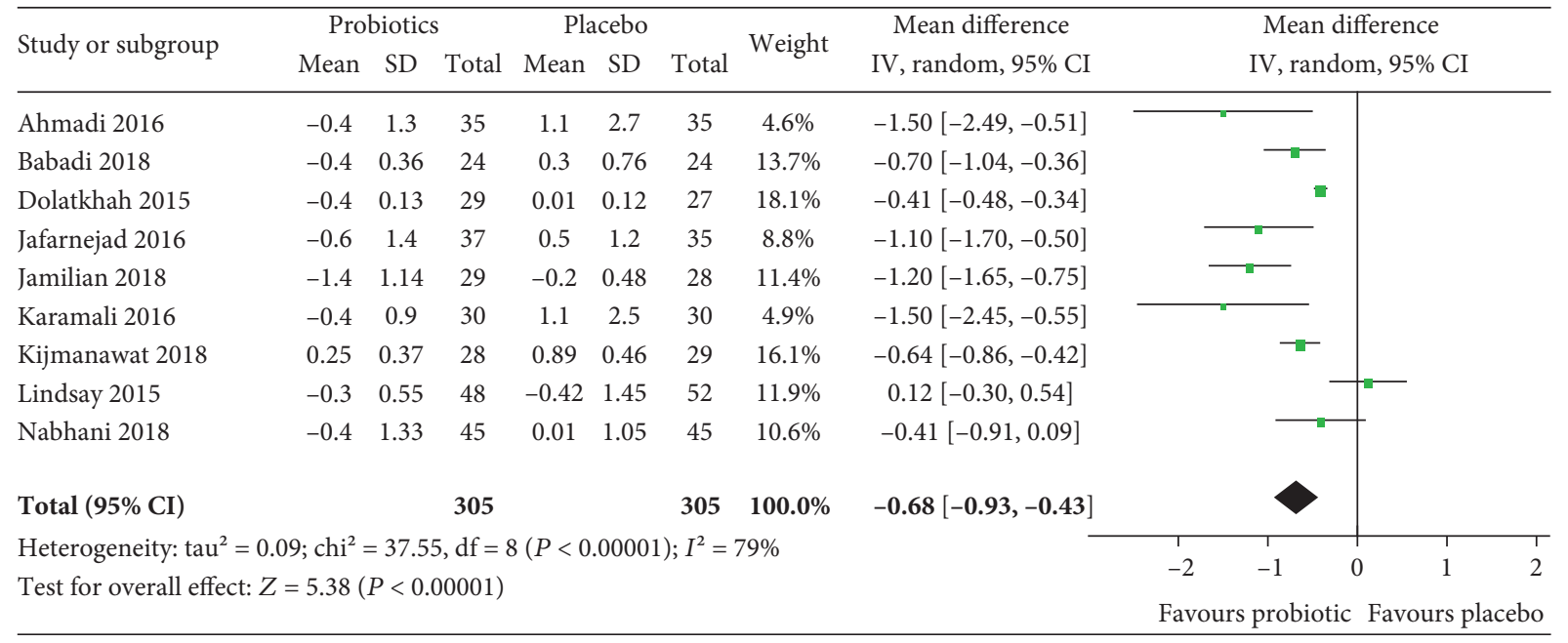

(c)

Figure 4: Continued. 


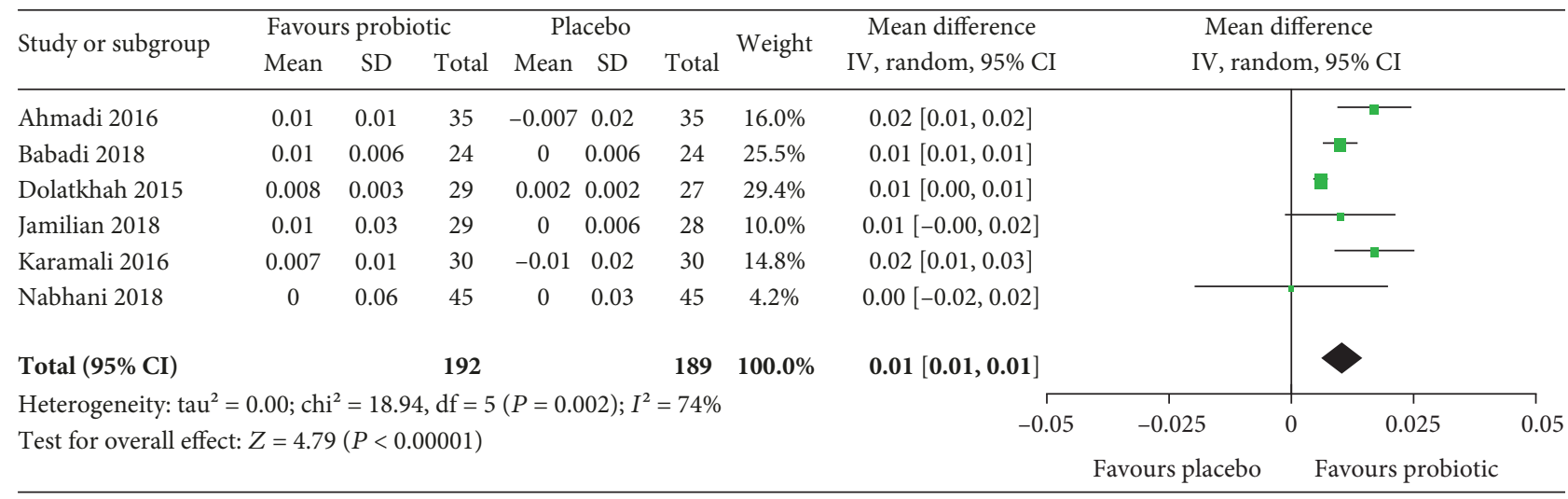

(d)

FIGURE 4: Effect of probiotic supplementation on blood glucose and related indicators: (a) FBG (mg/dL), (b) FSI ( $\mu \mathrm{IU} / \mathrm{mL}),(\mathrm{c}) \mathrm{HOMA}-\mathrm{IR}$, and (d) QUICKI in pregnant women with gestational diabetes.

mean age of participants is a potential source of the substantial heterogeneity. Sensitivity analyses by excluding the studies with high risk bias showed that the results of metaanalyses were robust. The number of studies was smaller than 10 in all meta-analyses except the one for FBG. The funnel plot constructed based on the data for FBG was visually symmetric (Figure 7), providing no evidence for publication bias.

\section{Discussion}

This systematic review included 11 trials and assessed the effects of probiotic supplementation for 4-8 weeks on pregnancy outcomes, glycemic control, lipid profiles, and biomarkers of inflammation and oxidative stress in pregnant women with GDM. We identified three published systematic reviews that were similar to but actually different from the present one. Specifically, the systematic review by Taylor et al. [12] was interested in the effects of probiotics for treating GDM (i.e., conducted in women with GDM) but included only four trials. The systematic reviews by Peng et al. [38] and Zheng et al. [39] both included more than 10 trials, but among them, only four or five unique trials were conducted to assess the effects of probiotics for treating GDM (i.e., conducted in women with GDM), while the other trials assessed the preventive effects of probiotics (i.e., conducted in women without GDM) which is not relevant to the objective of the present systematic review. In addition, the three previous systematic reviews were mainly focused on glycemic control and lipid profiles. The main strength of the present review is that it included much more trials than previous ones, with most of the trials at a low risk of bias, and investigated both hard and surrogate outcomes.

Our meta-analyses showed that probiotic supplementation in women with GDM reduced the incidence of a newborn's hyperbilirubinemia and improved HDL-cholesterol and four biomarkers related to inflammation and oxidative stress, with no or low heterogeneity among studies. However, whether these results are sufficient to support the use of probiotics in the management of GDM remains uncertain, for two reasons. First, most of the above outcomes are surrogate markers rather than patient-important clinical endpoints.
For example, inflammation and oxidative stress measures were investigated by some of the included studies because they were believed to be associated with cardiovascular disease $[24,32]$. However, this argument is mainly based on low-level evidence from small cross-sectional or retrospective studies $[40,41]$. Few prospective studies are available to corroborate the hypothesis that they are predictive of cardiovascular disease in later life in women with GDM. Even if the association does exist, the number of CVD events that are attributable to the change in those surrogate markers and the number of events that can be prevented by probiotics supplementation remain unknown. Thus, it may be hard to determine the clinical significance of the effects of probiotics based on currently available studies. Second, almost all studies included in the meta-analyses for the above outcomes (except one study for HDL-cholesterol) [35] were from Iran. It is unclear if there was any systematic difference between the Iranian studies and those from other countries. For example, in the meta-analyses on HDL-cholesterol (Figure 5(d)), the point effect estimates of Iranian studies all favored probiotics, whereas the effect estimate in Lindsay et al.'s study, which was from Ireland, favored the control group. If this was indeed a result from different countries of study (e.g., the study population or methodology was systematically different), the generalizability of our meta-analysis results would be undermined.

Our meta-analyses also found that probiotics could improve glycemic control and reduce triglyceride, but there was substantial heterogeneity among studies. Prespecified subgroup analyses according to age and intervention type showed that the heterogeneity was substantially reduced or even disappeared in a few subgroups, but persisted in most others (Table 2). A possible explanation for this is that the potential effect modification by the two subgroup factors could not be effectively investigated by our subgroup analyses, as the subgroups were formed based on aggregate data rather than individual data (which was not available to us) and they were not distinct from each other in terms of the status of the subgroup factor. For example, the subgroups with a mean age $<30$ years actually had some participants older than 30 years, and similarly, those with a mean age $\geq$ 


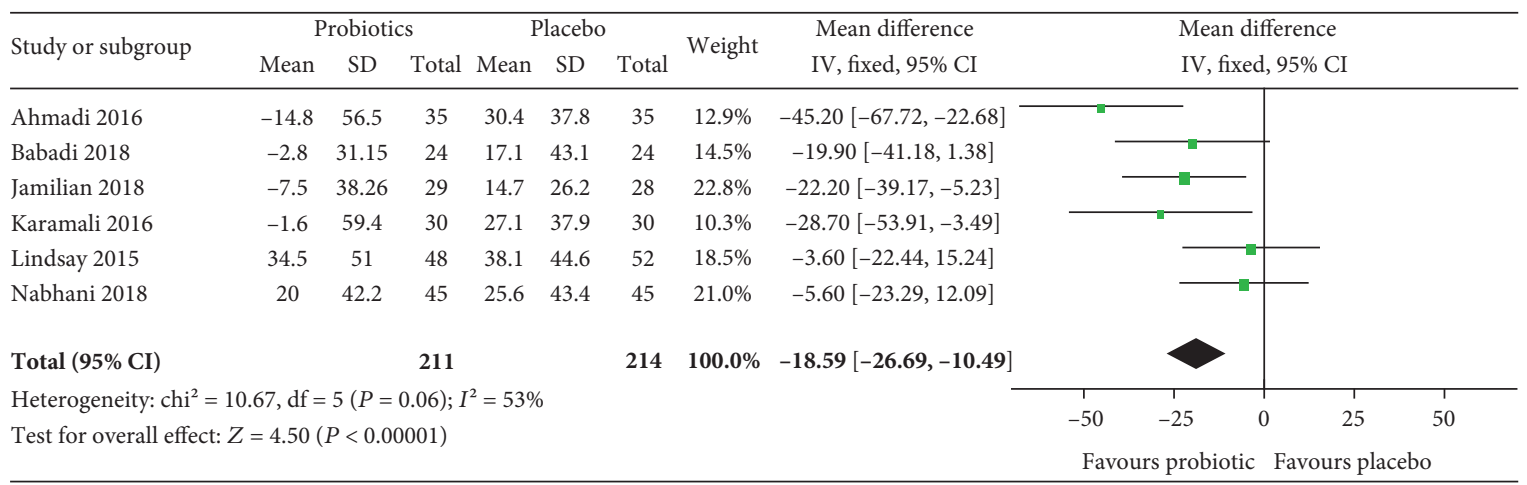

(a)

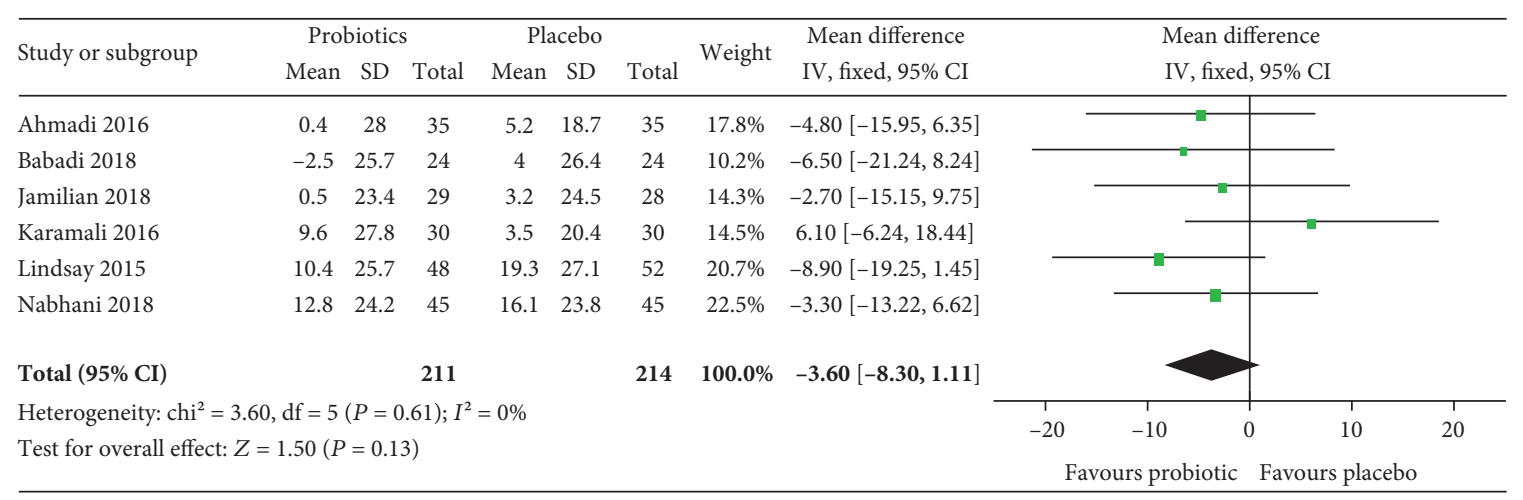

(b)

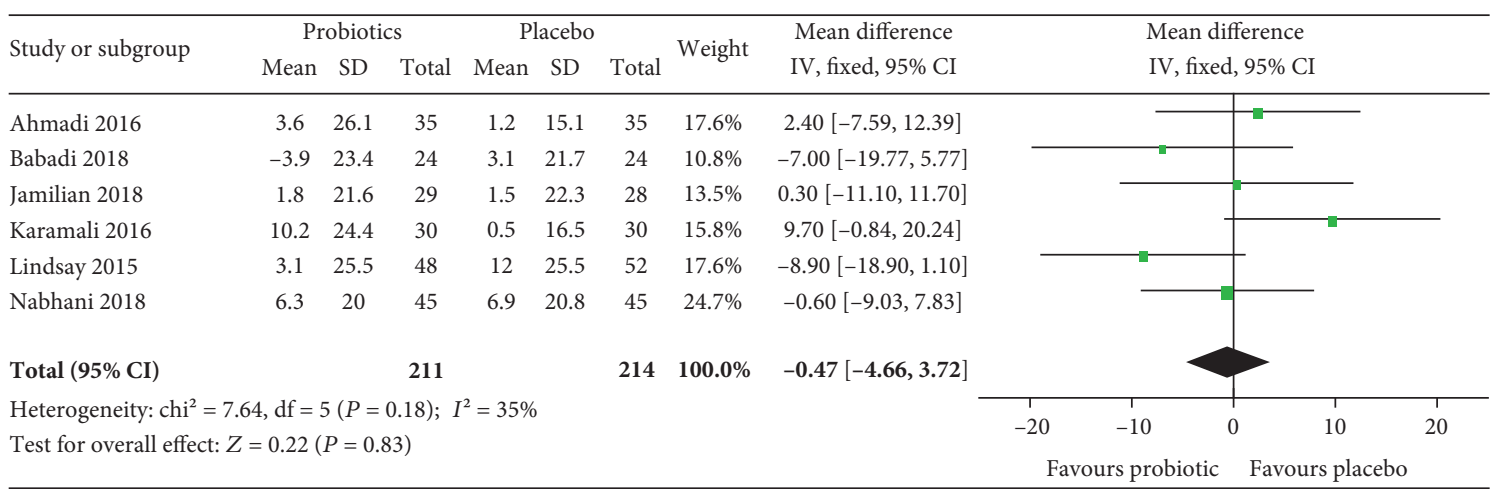

(c)

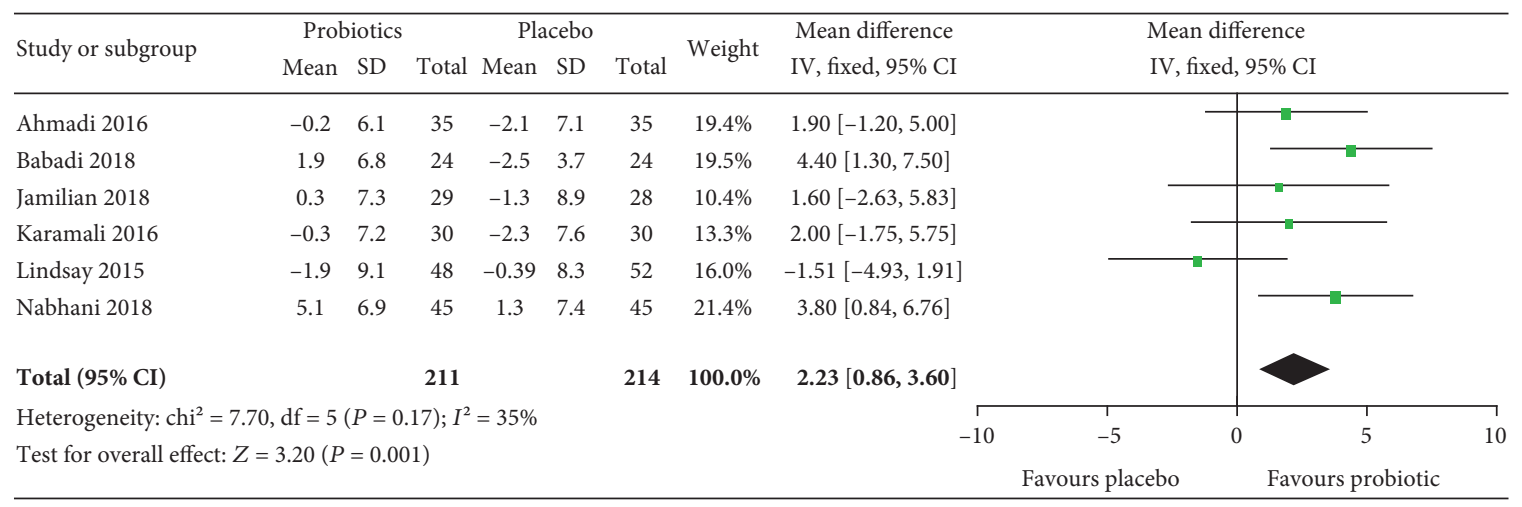

(d)

FIGURE 5: Effect of probiotic supplementation on blood lipid profiles: (a) triglycerides (mg/dL), (b) total cholesterol (mg/dL), (c) LDLcholesterol (mg/dl), and (d) HDL-cholesterol (mg/dL) in pregnant women with gestational diabetes. 


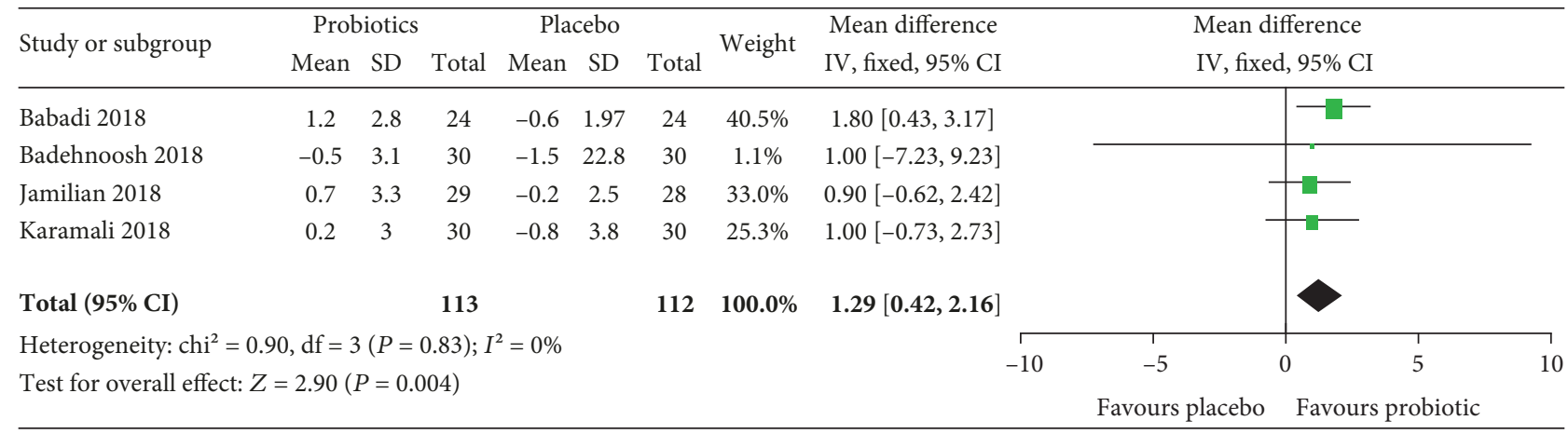

(a)

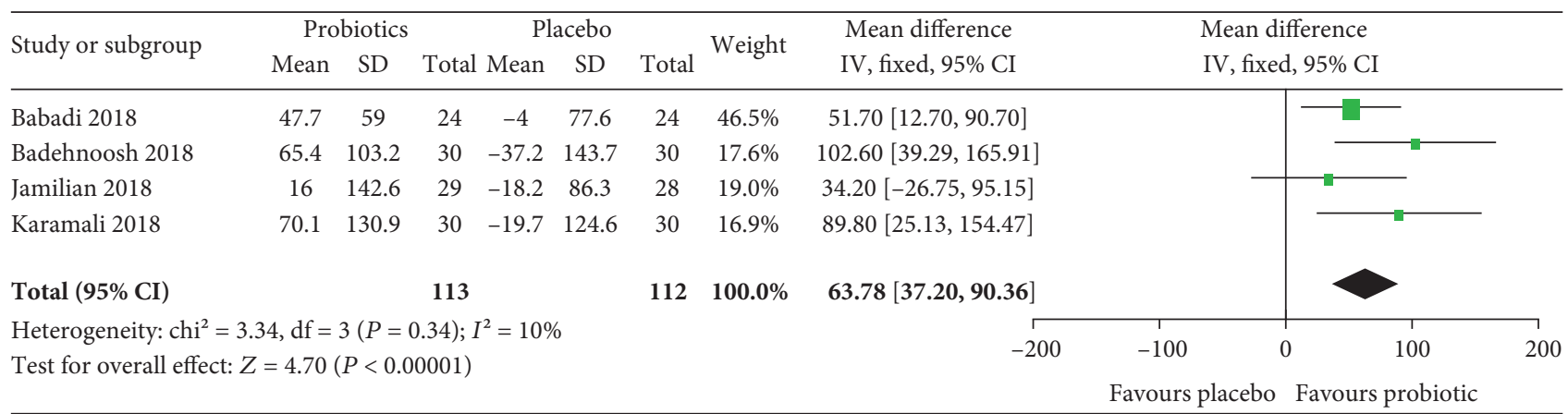

(b)

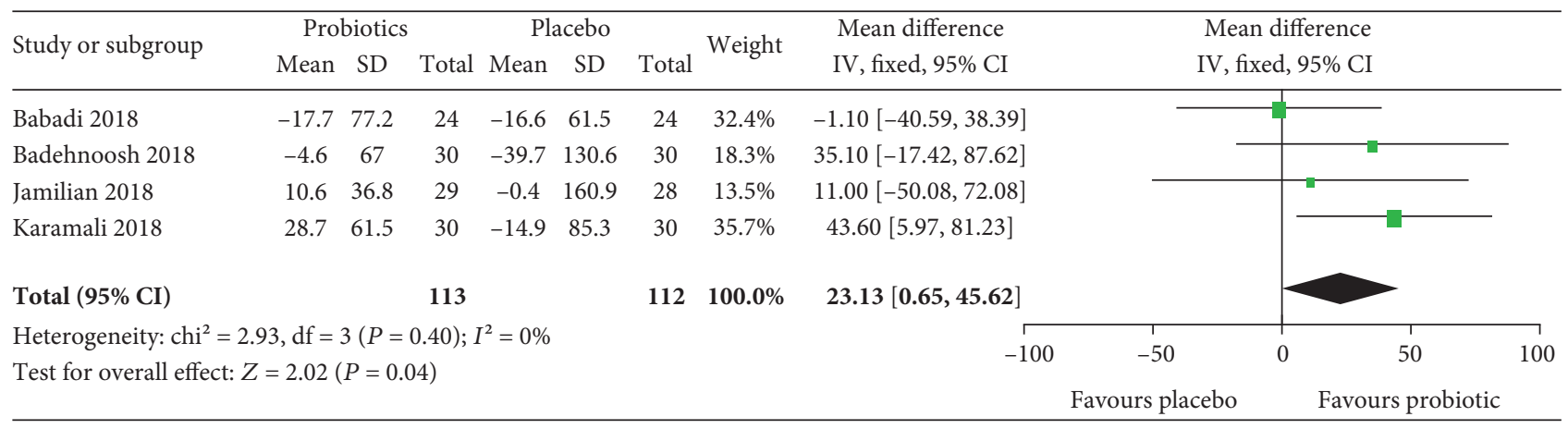

(c)

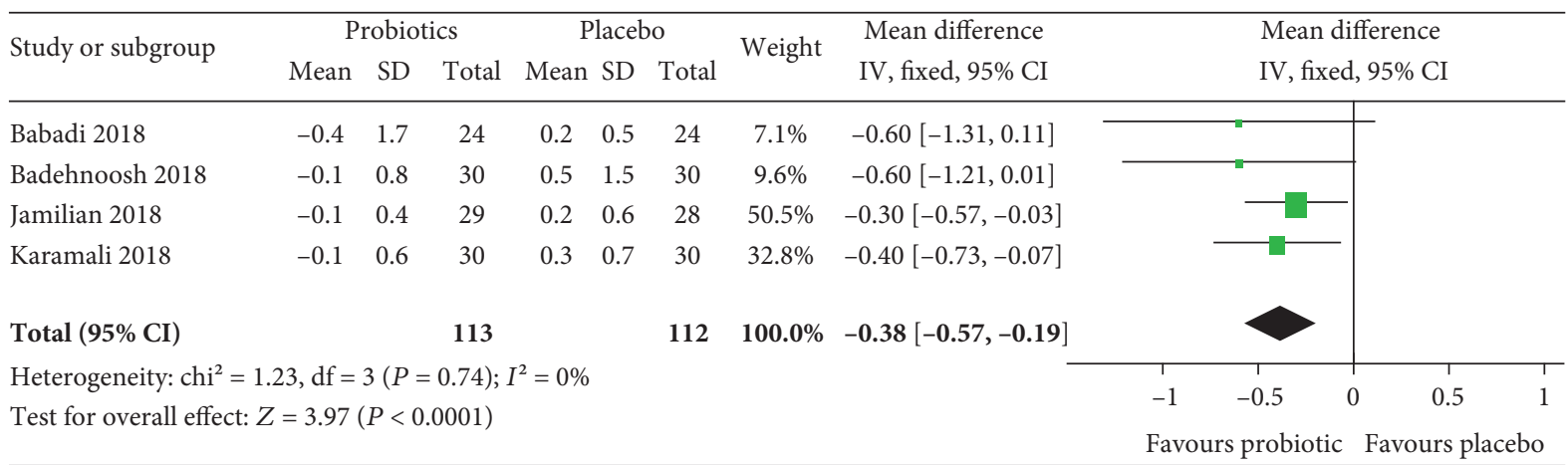

(d)

FIGURE 6: Effect of probiotic supplementation on biomarkers of inflammation and oxidative stress: (a) NO ( $\mu \mathrm{mol} / \mathrm{L}),(\mathrm{b}) \mathrm{TAC}(\mathrm{mmol} / \mathrm{L})$, (c) $\mathrm{GSH}(\mu \mathrm{mol} / \mathrm{L})$, and $(\mathrm{d}) \mathrm{MDA}(\mu \mathrm{mol} / \mathrm{L})$ in pregnant women with gestational diabetes.

30 years had some participants younger than 30 years. This issue might lead to ecological bias and undermine the validity of subgroup comparison. Another possible explanation is that the substantial heterogeneity was mainly caused by other factors than age and intervention type, e.g., the species and dosage of probiotics. However, limited available data 
TABLE 2: The results of subgroup analysis according to intervention type and age.

\begin{tabular}{|c|c|c|c|c|c|}
\hline Subgroup & Studies & Patients & Mean difference $(95 \% \mathrm{CI})$ unless other specified & Heterogeneity $\left(I^{2}\right) \%$ & $P$ value \\
\hline \multicolumn{6}{|c|}{ Macrosomia } \\
\hline \multicolumn{6}{|c|}{ Intervention } \\
\hline Probiotics & 3 & 264 & $0.47(0.10,2.15)^{*}$ & 56 & 0.47 \\
\hline Synbiotics & 1 & 60 & $0.14(0.01,2.65)^{*}$ & & \\
\hline \multicolumn{6}{|l|}{ Mean age } \\
\hline$<30$ & 2 & 120 & $0.13(0.02,1.08)^{*}$ & 0 & 0.09 \\
\hline$\geq 30$ & 2 & 204 & $0.89(0.45,1.77)^{*}$ & 64 & \\
\hline \multicolumn{6}{|l|}{ FBG } \\
\hline \multicolumn{6}{|c|}{ Intervention } \\
\hline Probiotics & 8 & 510 & $-4.08(-4.90,-3.26)$ & 95 & 0.49 \\
\hline Synbiotics & 2 & 160 & $-2.75(-6.42,0.92)$ & 0 & \\
\hline \multicolumn{6}{|l|}{ Mean age } \\
\hline$<30$ & 5 & 324 & $-6.84(-7.96,-5.72)$ & 63 & $<0.00001$ \\
\hline$\geq 30$ & 5 & 346 & $-1.15(-2.28,-0.01)$ & 94 & \\
\hline \multicolumn{6}{|l|}{ FSI } \\
\hline \multicolumn{6}{|c|}{ Intervention } \\
\hline Probiotics & 7 & 450 & $-2.24(-3.28,-1.20)$ & 81 & 0.54 \\
\hline Synbiotics & 2 & 160 & $-3.90(-9.07,1.27)$ & 57 & \\
\hline \multicolumn{6}{|l|}{ Mean age } \\
\hline$<30$ & 4 & 264 & $-1.40(-1.67,-1.13)$ & 64 & 0.007 \\
\hline$\geq 30$ & 5 & 346 & $-2.41(-3.10,-1.72)$ & 80 & \\
\hline \multicolumn{6}{|l|}{ HOMA-IR } \\
\hline \multicolumn{6}{|c|}{ Intervention } \\
\hline Probiotics & 7 & 450 & $-0.67(-0.94,-0.40)$ & 82 & 0.72 \\
\hline Synbiotics & 3 & 160 & $-0.87(-1.92,-0.19)$ & 73 & \\
\hline \multicolumn{6}{|l|}{ Mean age } \\
\hline$<30$ & 4 & 264 & $-0.42(-0.49,-0.36)$ & 59 & 0.01 \\
\hline$\geq 30$ & 5 & 346 & $-0.66(-0.83,-0.49)$ & 83 & \\
\hline \multicolumn{6}{|l|}{ QUICKI } \\
\hline \multicolumn{6}{|c|}{ Intervention } \\
\hline Probiotics & 4 & 221 & $0.01(0.01,0.01)$ & 74 & 0.86 \\
\hline Synbiotics & 2 & 160 & $0.01(0.01,0.03)$ & 60 & \\
\hline \multicolumn{6}{|l|}{ Mean age } \\
\hline$<30$ & 4 & 264 & $0.01(0.01,0.01)$ & 76 & 0.02 \\
\hline$\geq 30$ & 2 & 117 & $0.01(0.01,0.02)$ & 0 & \\
\hline \multicolumn{6}{|c|}{ Triglycerides } \\
\hline \multicolumn{6}{|c|}{ Intervention } \\
\hline Probiotics & 4 & 265 & $-17.51(-27.47,-7.54)$ & 6 & 0.71 \\
\hline Synbiotics & 2 & 160 & $-20.71(-34.62,-6.80)$ & 86 & \\
\hline \multicolumn{6}{|l|}{ Mean age } \\
\hline$<30$ & 3 & 208 & $-20.47(-32.11,-8.82)$ & 73 & 0.66 \\
\hline$\geq 30$ & 3 & 217 & $-16.84(-28.12,-5.56)$ & 36 & \\
\hline
\end{tabular}

${ }^{*}$ The effect measure is the risk ratio (95\% CI). GDM: gestational diabetes mellitus; FBG: fasting blood glucose; FSI: fasting serum insulin; HOMA-IR: homeostasis model assessment insulin resistance; QUICKI: quantitative insulin sensitivity check index.

precluded us from doing further analyses on these factors. In addition, because of the surrogate nature of outcomes and the fact that the included studies are mostly from Iran, as mentioned above, the clinical significance and generalizability of the meta-analysis results on glycemic control and triglyceride are also uncertain.

In summary, the results of this systematic review should be interpreted with the following limitations taken into 


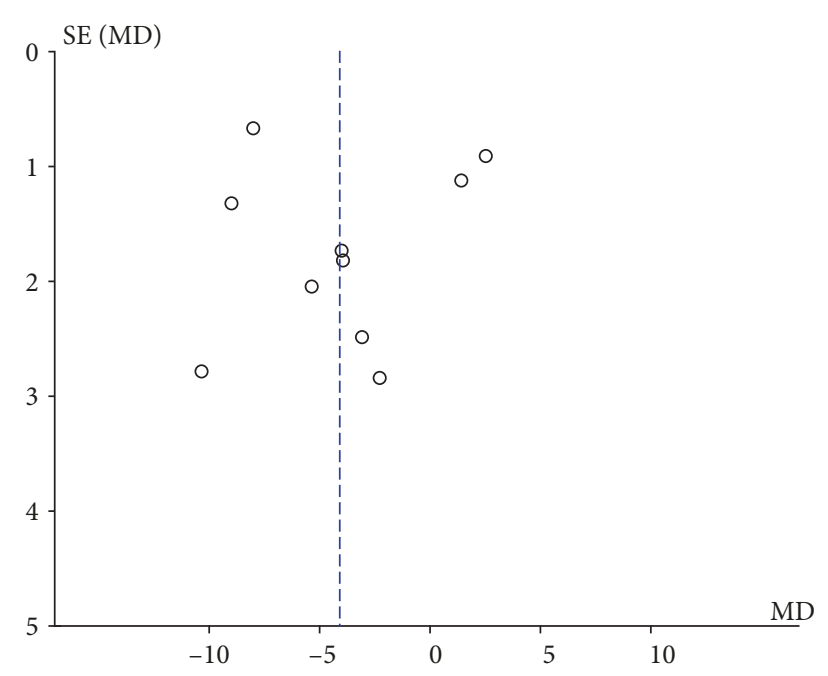

Figure 7: Funnel plot of included articles based on the data for FBG.

account: First, there was substantial heterogeneity in some of the meta-analyses, which was associated with but could not be completely attributable to the mean age of participants and intervention type. Other causes for the substantial heterogeneity remain to be investigated. Second, the fact that most studies came from Iran may undermine the generalizability of results to some extent. Third, potential publication bias could not be investigated effectively owing to the small number of studies included in most meta-analyses. Further studies conducted in different races of population, with larger sample size and focusing on hard outcomes rather than surrogate markers, are needed to validate the health effects of probiotics in women with GDM.

\section{Conclusions}

In conclusion, probiotic supplementation seemed to be able to reduce the risk of a newborn's hyperbilirubinemia and improve glycemic control, blood lipid profiles, and inflammation and oxidative stress in pregnant women with GDM. However, due to the heterogeneity among existing studies, the surrogate nature of outcomes, and/or the fact that most studies were from Iran, the clinical significance and generalizability of the above findings remain uncertain. Further studies are warranted to address the limitations of existing evidence and better inform the management of GDM.

\section{Conflicts of Interest}

Jiayue Zhang, Shujuan Ma, Shilan Wu, Chuhao Guo, Sisi Long, and Hongzhuan Tan have no conflicts of interest.

\section{Authors' Contributions}

Jiayue Zhang and Shujuan Ma designed the research. Shilan $\mathrm{Wu}$ and Chuhao Guo conducted the research. Sisi Long analyzed the data. Jiayue Zhang wrote the paper, and Hongzhuan Tan revised the paper. Jiayue Zhang had primary responsibility for the final content. All authors read and approved the final manuscript.

\section{Acknowledgments}

This work was supported by the National Natural Science Foundation of China (grant \# 81773535) and Key Research and Development Program of Hunan Province (grant \# 2018SK2061).

\section{References}

[1] T. A. Buchanan and A. H. Xiang, "Gestational diabetes mellitus," The Journal of Clinical Investigation, vol. 115, no. 3, pp. 485-491, 2005.

[2] E. Chiefari, B. Arcidiacono, D. Foti, and A. Brunetti, "Gestational diabetes mellitus: an updated overview," Journal of Endocrinological Investigation, vol. 40, no. 9, pp. 899-909, 2017.

[3] D. D. Briana, M. Boutsikou, A. Marmarinos, D. Gourgiotis, and A. Malamitsi-Puchner, "Perinatal sclerostin concentrations in abnormal fetal growth: the impact of gestational diabetes," The Journal of Maternal-Fetal \& Neonatal Medicine, vol. 32, no. 13, pp. 2228-2232, 2018.

[4] J. Huynh, G. Xiong, and R. Bentley-Lewis, "A systematic review of metabolite profiling in gestational diabetes mellitus," Diabetologia, vol. 57, no. 12, pp. 2453-2464, 2014.

[5] Z. Rimar, V. Milas, M. Medimurec, and I. Mesic, "Respiratory distress syndrome in newborns of gestational age of over 32 weeks," Collegium Antropologicum, vol. 38, no. 2, pp. 621626, 2014.

[6] B. R. Shah, R. Retnakaran, and G. L. Booth, "Increased risk of cardiovascular disease in young women following gestational diabetes mellitus," Diabetes Care, vol. 31, no. 8, pp. 1668-1669, 2008.

[7] A. Homayouni Rad, R. Torab, M. Ghalibaf, S. Norouzi, and E. V. Mehrabany, "Might patients with immune-related diseases benefit from probiotics?," Nutrition, vol. 29, no. 3, pp. 583-586, 2013.

[8] A. Homayouni Rad, R. Torab, A. M. Mortazavian, E. V. Mehrabany, and L. V. Mehrabany, "Can probiotics prevent or improve common cold and influenza?," Nutrition, vol. 29, no. 5, pp. 805-806, 2013.

[9] A. H. Rad, S. Abbasalizadeh, S. Vazifekhah et al., "The future of diabetes management by healthy probiotic microorganisms," Current Diabetes Reviews, vol. 13, no. 6, pp. 582-589, 2017.

[10] B. C. Johnston, A. L. Supina, and S. Vohra, "Probiotics for pediatric antibiotic-associated diarrhea: a meta-analysis of randomized placebo-controlled trials," CMAJ, vol. 175 , no. 4 , pp. 377-383, 2006.

[11] H. S. Lye, C. Y. Kuan, J. A. Ewe, W. Y. Fung, and M. T. Liong, "The improvement of hypertension by probiotics: effects on cholesterol, diabetes, renin, and phytoestrogens," International Journal of Molecular Sciences, vol. 10, no. 9, pp. 3755-3775, 2009.

[12] B. L. Taylor, G. E. Woodfall, K. E. Sheedy et al., "Effect of probiotics on metabolic outcomes in pregnant women with gestational diabetes: a systematic review and meta-analysis of randomized controlled trials," Nutrients, vol. 9, no. 5, p. 461, 2017.

[13] H. Asgharian, A. Homayouni-Rad, M. Mirghafourvand, and S. Mohammad-Alizadeh-Charandabi, "Effect of probiotic yoghurt on plasma glucose in overweight and obese pregnant women: a randomized controlled clinical trial," European Journal of Nutrition, 2019.

[14] M. Mirghafourvand, A. Homayouni Rad, S. Mohammad Alizadeh Charandabi, Z. Fardiazar, and K. Shokri, "The effect of probiotic yogurt on constipation in pregnant women: 
a randomized controlled clinical trial," Iranian Red Crescent Medical Journal, vol. 18, no. 11, article e39870, 2016.

[15] A. Homayouni, P. Bastani, S. Ziyadi et al., "Effects of probiotics on the recurrence of bacterial vaginosis: a review," Journal of Lower Genital Tract Disease, vol. 18, no. 1, pp. 79-86, 2014.

[16] A. Jarde, A. M. Lewis-Mikhael, P. Moayyedi et al., "Pregnancy outcomes in women taking probiotics or prebiotics: a systematic review and meta-analysis," BMC Pregnancy and Childbirth, vol. 18, no. 1, p. 14, 2018.

[17] A. Homayoni Rad, E. V. Mehrabany, B. Alipoor, L. V. Mehrabany, and M. Javadi, "Do probiotics act more efficiently in foods than in supplements?," Nutrition, vol. 28, no. 7-8, pp. 733-736, 2012.

[18] A. Homayoni Rad, E. Vaghef Mehrabany, B. Alipoor, and L. Vaghef Mehrabany, "The comparison of food and supplement as probiotic delivery vehicles," Critical Reviews in Food Science and Nutrition, vol. 56, no. 6, pp. 896-909, 2016.

[19] M. S. Alokail, S. Sabico, Y. al-Saleh et al., "Effects of probiotics in patients with diabetes mellitus type 2: study protocol for a randomized, double-blind, placebo-controlled trial," Trials, vol. 14, no. 1, p. 195, 2013.

[20] L. Bordalo Tonucci, K. M. O. Dos Santos, C. L. de Luces Fortes Ferreira, S. M. R. Ribeiro, L. L. de Oliveira, and H. S. D. Martino, "Gut microbiota and probiotics: focus on diabetes mellitus," Critical Reviews in Food Science and Nutrition, vol. 57, no. 11, pp. 2296-2309, 2017.

[21] H. S. Ejtahed, J. Mohtadi-Nia, A. Homayouni-Rad, M. Niafar, M. A. Jafarabadi, and V. Mofid, "The effects of probiotic and conventional yoghurt on diabetes markers and insulin resistance in type 2 diabetic patients: a randomized controlled clinical trial," Iranian Journal of Endocrinology and Metabolism, vol. 13, p. 112, 2011.

[22] H. S. Ejtahed, J. Mohtadi-Nia, A. Homayouni-Rad et al., "Effect of probiotic yogurt containing Lactobacillus acidophilus and Bifidobacterium lactis on lipid profile in individuals with type 2 diabetes mellitus," Journal of Dairy Science, vol. 94, no. 7, pp. 3288-3294, 2011.

[23] R. Mobini, V. Tremaroli, M. Ståhlman et al., "Metabolic effects of Lactobacillus reuteri DSM 17938 in people with type 2 diabetes: a randomized controlled trial," Diabetes, Obesity and Metabolism, vol. 19, no. 4, pp. 579-589, 2017.

[24] M. Babadi, A. Khorshidi, E. Aghadavood et al., "The effects of probiotic supplementation on genetic and metabolic profiles in patients with gestational diabetes mellitus: a randomized, double-blind, placebo-controlled trial," Probiotics and Antimicrobial Proteins, 2018.

[25] S. Ahmadi, M. Jamilian, M. Tajabadi-Ebrahimi, P. Jafari, and Z. Asemi, "The effects of synbiotic supplementation on markers of insulin metabolism and lipid profiles in gestational diabetes: a randomised, double-blind, placebo-controlled trial," The British Journal of Nutrition, vol. 116, no. 8, pp. 1394-1401, 2016.

[26] D. Moher, A. Liberati, J. Tetzlaff, and D. G. Altman, "Preferred reporting items for systematic reviews and meta-analyses: the PRISMA statement," International Journal of Surgery, vol. 8, no. 5, pp. 336-341, 2010.

[27] J. P. T. Higgins, D. G. Altman, P. C. Gotzsche et al., "The Cochrane Collaboration's tool for assessing risk of bias in randomised trials," BMJ, vol. 343, no. 2, article d5928, 2011.

[28] H. JPT and S. Green, Cochrane Handbook for Systematic Reviews of Interventions Version 5.1.0 [updated March 2011],
The Cochrane Collaboration, 2011, http://www.handbook. cochrane.org.

[29] B. Badehnoosh, M. Karamali, M. Zarrati et al., "The effects of probiotic supplementation on biomarkers of inflammation, oxidative stress and pregnancy outcomes in gestational diabetes," The Journal of Maternal-Fetal \& Neonatal Medicine, vol. 31, no. 9, pp. 1128-1136, 2018.

[30] N. Dolatkhah, M. Hajifaraji, F. Abbasalizadeh, N. Aghamohammadzadeh, Y. Mehrabi, and M. Mesgari Abbasi, "Is there a value for probiotic supplements in gestational diabetes mellitus? A randomized clinical trial," Journal of Health, Population and Nutrition, vol. 33, no. 1, p. 25, 2015.

[31] S. Jafarnejad, S. Saremi, F. Jafarnejad, and A. Arab, "Effects of a multispecies probiotic mixture on glycemic control and inflammatory status in women with gestational diabetes: a randomized controlled clinical trial," Journal of Nutrition and Metabolism, vol. 2016, Article ID 5190846, 8 pages, 2016.

[32] M. Jamilian, E. Amirani, and Z. Asemi, "The effects of vitamin $\mathrm{D}$ and probiotic co-supplementation on glucose homeostasis, inflammation, oxidative stress and pregnancy outcomes in gestational diabetes: a randomized, double-blind, placebocontrolled trial," Clinical Nutrition, 2018.

[33] M. Karamali, N. Nasiri, N. Taghavi Shavazi et al., "The effects of synbiotic supplementation on pregnancy outcomes in gestational diabetes," Probiotics Antimicrob Proteins., vol. 10, no. 3, pp. 496-503, 2018.

[34] A. Kijmanawat, P. Panburana, S. Reutrakul, and C. Tangshewinsirikul, "Effects of probiotic supplements on insulin resistance in gestational diabetes mellitus: a doubleblind randomized controlled trial," Journal of Diabetes Investigation, vol. 10, no. 1, pp. 163-170, 2019.

[35] K. L. Lindsay, L. Brennan, M. A. Kennelly et al., "Impact of probiotics in women with gestational diabetes mellitus on metabolic health: a randomized controlled trial," American Journal of Obstetrics and Gynecology, vol. 212, no. 4, pp. 496.e1-496.e11, 2015.

[36] Z. Nabhani, S. J. G. Hezaveh, E. Razmpoosh, M. AsghariJafarabadi, and B. P. Gargari, "The effects of synbiotic supplementation on insulin resistance/sensitivity, lipid profile and total antioxidant capacity in women with gestational diabetes mellitus: a randomized double blind placebo controlled clinical trial," Diabetes Research and Clinical Practice, vol. 138, pp. 149-157, 2018.

[37] M. Karamali, F. Dadkhah, M. Sadrkhanlou et al., "Effects of probiotic supplementation on glycaemic control and lipid profiles in gestational diabetes: a randomized, double-blind, placebo-controlled trial," Diabetes \& Metabolism, vol. 42, no. 4, pp. 234-241, 2016.

[38] T. R. Peng, T. W. Wu, and Y. C. Chao, "Effect of probiotics on the glucose levels of pregnant women: a meta-analysis of randomized controlled trials," Medicina, vol. 54, no. 5, p. 77, 2018.

[39] J. Zheng, Q. Feng, S. Zheng, and X. Xiao, "The effects of probiotics supplementation on metabolic health in pregnant women: an evidence based meta-analysis," PLoS One, vol. 13, no. 5, article e0197771, 2018.

[40] A. Bastani, S. Rajabi, A. Daliran, H. Saadat, and F. KarimiBusheri, "Oxidant and antioxidant status in coronary artery disease," Biomedical Reports, vol. 9, no. 4, pp. 327-332, 2018.

[41] A. Gawron-Skarbek, J. Chrzczanowicz, J. Kostka et al., "Cardiovascular risk factors and total serum antioxidant capacity in healthy men and in men with coronary heart disease," BioMed Research International, vol. 2014, Article ID 216964, 8 pages, 2014. 


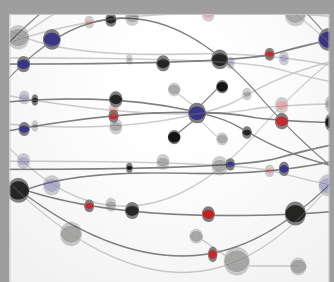

The Scientific World Journal
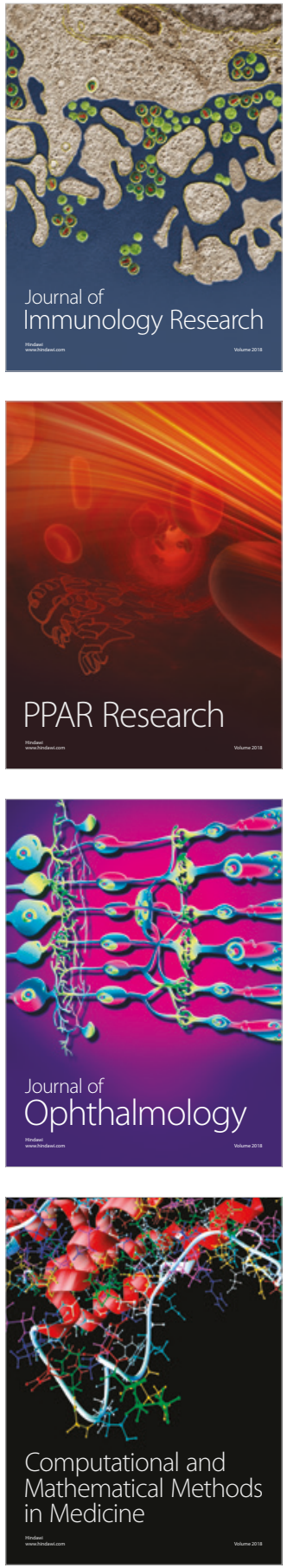

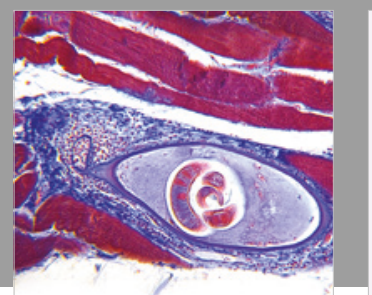

Gastroenterology Research and Practice

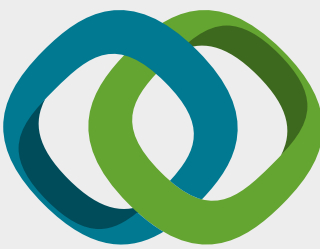

\section{Hindawi}

Submit your manuscripts at

www.hindawi.com
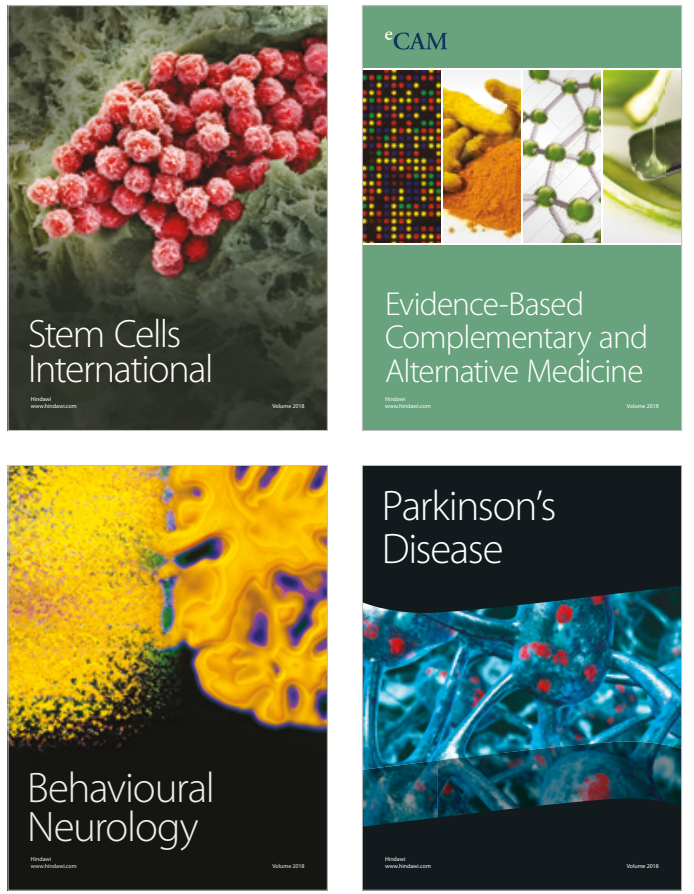

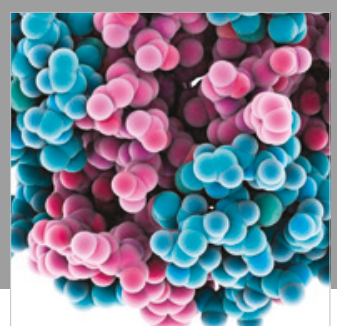

ournal of

Diabetes Research

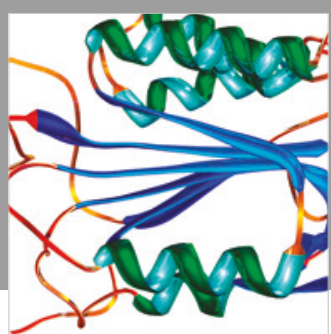

Disease Markers
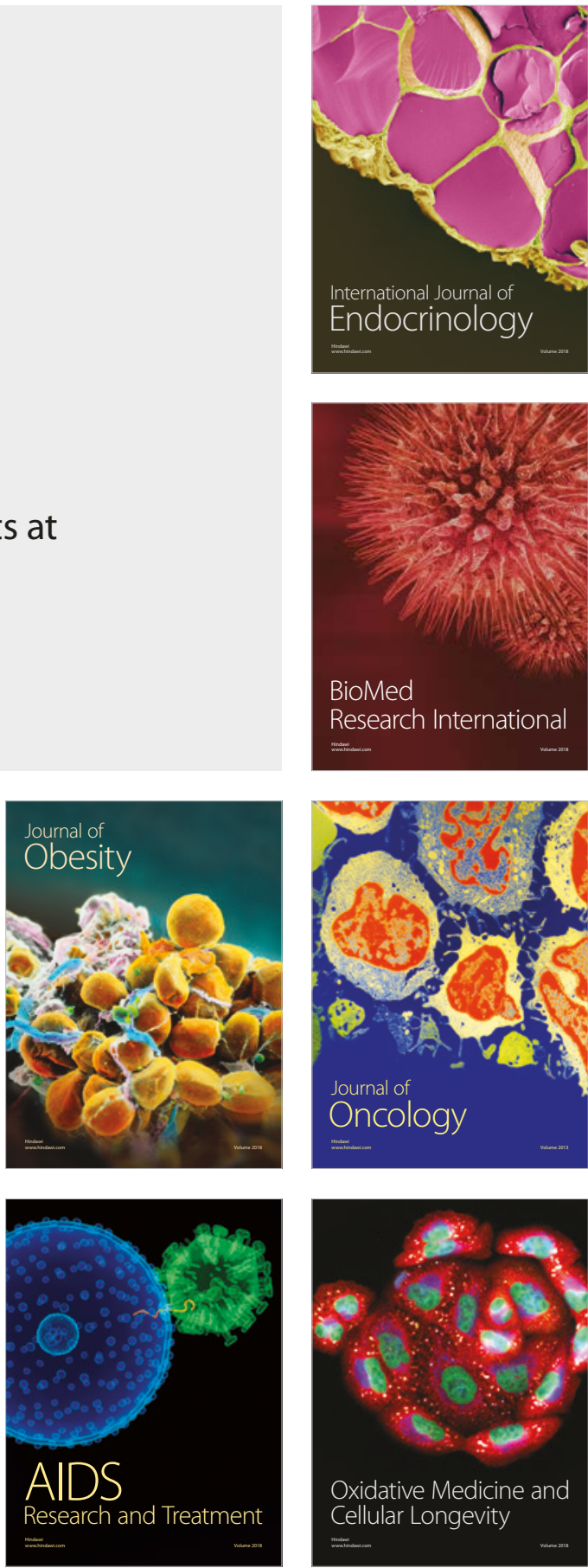